Aksaray University
Journal of Science and Engineering
e-ISSN: 2587-1277
http://dergipark.gov.tr/asujse
http://asujse.aksaray.edu.tr

\title{
Research of Required Qualifications for Baby Clothes from Past to Present
}

\author{
Zumrut Bahadir Unal*, Serra Sekeroglu \\ Ege University, Engineering Faculty, Department of Textile Engineering, Bornova, 35100, Turkey
}

-Received Date: 21 Mar $2017 \quad$-Revised Date: 05 Jul $2017 \quad$ •Accepted Date: 26 Jul $2017 \quad$-Published Online: 17 Aug 2017

\begin{abstract}
Clothing fabrics go through a series of stages before production stage. Many processes such as bleaching, dyeing, etc. are made with various chemicals. These chemicals must finally be removed from the product by washing. However, it is not possible to completely eliminate some chemicals from the surface. Surfaces on textile that are harmful to health when in contact with skin are at risk in terms of cloth production. In particular, the surfaces used in baby and child outfits should be examined more rigorously. Within the context of "Textile Ecology", harmful chemicals used in clothing production, especially in the last 20 years, have been reduced as much as possible and acceptable limit values have been determined. Therefore, it is expected that the fabrics to be used in baby clothes are subjected to various tests and their compliance with the limit values is examined. Baby skin has a much thinner, less sturdy and delicate feature than adults. For this reason, it is important that the materials used in baby products should not have any risk factors for health. It is desired that the model and material properties must be composed of materials that do not irritate the skin, give a feeling of comfort, and do not trigger allergic disorders.

Within the scope of this study, it is aimed to give general information about Oeko-Tex and ecological textile issue, to research the test standards should be infants clothing under 3 years from past to present and to see the rates that can damage the skin and health.
\end{abstract}

\section{Keywords}

Baby clothing, chemical treatments, comfort, health, skin.

*Corresponding Author: Zumrut Bahadir Unal, zumrut.bahadir.unal@ege.edu.tr 


Aksaray University
Journal of Science and Engineering
e-ISSN: 2587-1277
http://dergipark.gov.tr/asujse
http://asujse.aksaray.edu.tr

\title{
Bebek Giysilerinde Aranan Kriterlerin Geçmişten Günümüze Değerlendirilmesi
}

\author{
Zümrüt Bahadır Ünal*, Serra Şekeroğlu \\ Ege Üniversitesi, Mühendislik Fakültesi, Tekstil Mühendisliği, Bornova, 35100, Türkiye
}

•Gönderi Tarihi: 21 Mar 2017

-Kabul Tarihi: 05 Tem 2017

-Kabul Tarihi:26 Tem 2017

-Çevrimiçi Yayın Tarih: 17 Agu 2017

\section{Özet}

Giysilik kumaşlar, konfeksiyon üretimine gelmeden önce bir dizi aşamadan geçmektedir. Ağartma, boyama gibi birçok işlem çeşitli kimyasallarla birlikte yapılmaktadır. Bu kimyasallar, son olarak yıkamayla üründen mutlaka uzaklaştırılmalıdır. Ancak bazı kimyasalları yüzeyden tamamen uzaklaştırmak mümkün olmamaktadır. Tekstil üzerinde ciltle temas ettiğinde sağlık açısından zararlı olan yüzeyler, giysi üretimi açısından risklidir. Özellikle de bebek ve çocuk giyiminde kullanılan yüzeylerin çok daha titiz bir şekilde incelenmesi gerekmektedir. "Tekstil Ekolojisi” kavramı kapsamında, özellikle son 20 yılda giysi üretiminde kullanılan zararlı kimyasallar, mümkün derece azaltılmış ve kabul edilebilir limit değerleri belirlenmiştir. Dolayısıyla bebek giyiminde kullanılacak kumaşların da çeşitli testlere tabi tutularak limit değerlere olan uygunluklarına bakılması beklenmektedir. Bebek cildi ise, erişkinlere nazaran çok daha ince, dayanıksız ve hassas bir özelliğe sahip olduğundan bebek ürünlerinde kullanılan malzemelerin sağlık açısından herhangi bir risk unsuru taşımaması çok önemlidir. Model ve malzeme özelliklerinin cildi tahriş etmeyen, konfor hissi veren, alerjik rahatsızlıkları tetiklemeyen malzemelerden oluşması istenmektedir.

Bu çalışma kapsamında, Oeko-Tex ve ekolojik tekstil konusu hakkında genel bilgi verilmesi, 3 yaş altı bebekler için üretilen giysilerde olması gereken kalite test standartlarının geçmişten günümüze incelenmesi ve cilt ile sağlığa zarar verebilecek oranların görülmesi amaçlanmıştır.

\section{Anahtar Kelimeler}

Bebek giyimi, kimyasal işlemler, konfor, sağlık, cilt.

*Sorumlu Yazar: Zümrüt Bahadır Ünal, zumrut.bahadir.unal@ege.edu.tr 


\section{GíRİs}

Tüketici bilincinin artmasıyla birlikte, tüketiciler bebek ürünlerinin seçimi konusunda çok daha hassas kararlar almaya başlamışlardır. Çünkü bilinmektedir ki giysilerin amaca uygun ve konforlu olmasının yanı sıra malzemesinin cilde zarar vermemesi de çok önemlidir.

İyi kaliteye sahip giysiler profesyonelce üretilmeli, bedene iyi oturmalı, dayanıklı olmalı ve bu giysilerin üretiminde zararlı kimyasallar kullanılmamalıdır [1]. Tekstil ürünlerine uygulanan bazı işlemler, sadece insan sağlığına değil çevreye de önemli zararlar vermekte ve dünyanın sürdürülebilirliğini tehdit etmektedir. Bu nedenle elyaf üretiminden başlayarak giysi elde edilinceye kadar olan tüm üretim aşamalarında çevreye ve insanlara zarar verilmemesi amacına yönelik olan ekolojik tekstil bilinci, oldukça önemli bir konu haline gelmiştir. Bu amaçla da günümüzde bebek giysilerinde organik lifler veya daha hassas olarak üretilen ekolojik tekstiller tercih edilmektedir [2].

Ekolojik tekstil üzerine birçok çalışma yapılmıştır. Kurtoğlu ve Şenol'un yaptığı çalışmada tekstilde kullanılan insan sağlına zararlı boyarmaddeler incelenmiş̧tir [3]. Bulut'un çalışmasında 2 farklı tekstil markası seçilerek bu markalardan alınan ürünlerin kimyasal içerikleri incelenmiştir [4]. Cebeci, bir üniversitenin öğrencileri ile ekolojik tekstil bilinci hakkında anket yapmış, anket çalışmasına katılan öğrencilerin \%42'sinin "Ekolojik Tekstil" kavramını bilmesine karşın, \%65'inin eko etiketleri bilmediği görülmüştür [5]. Erdoğan ve arkadaşlarının çalışmasında tekstil ve hazır giyim ürünlerinde ekolojinin; üretim, insan ve çevre sağlı̆̆ı açısından önemi ile birlikte bir tekstil ürününün Eko-Teks standartlarına sahip olabilme koşulları değerlendirilmiştir [6]. Gümüşer'in çalışmasında ise bebek giysilerinde kullanılan doğal lifler ekolojik açıdan incelenmiştir. Günümüzde birçok önemli markanın, doğal lif kullanımını tercih etmeye başladığı vurgulanmıştır [2]. Wu ve arkadaşları Kenya ve Çin ülkelerinden temin ettikleri bebek giysileri üzerinde ekolojik testler yapmış ve elde ettikleri sonuçları karşılaştırmışlardır [1].

$\mathrm{Bu}$ çalışmayla birlikte, bebek giyiminde kullanılan yüzeylerde bulunabilen zararlı kimyasallar ile bu kimyasalların limit değerleri, geçmişten günümüze incelenerek tablolar yardımıyla karşılaştırılmıştır. Bu amaçla da 2007-2017 yılları arasında kabul edilebilir limit değerlerin yıllara göre değişimi incelenmiş̧tir.

\section{EKOLOJIK TEKSTIL ve EKOLOJIK BEBEK GIYYSILERİ}

Ekolojik tekstil; insan ve çevre sağlığına zarar vermeden üretilebilen, kullanılabilen ve yok edilebilen kısacası ekolojik dengeyi bozmayan ürünler olarak tanımlanmaktadır [3]. 
Bebek cildi oldukça hassas olduğu için dışarıdan gelebilecek zararlı maddeler, onların ciltlerine daha çok zarar vermektedir. Bu nedenle bebeklik döneminde eko tekstiller büyük bir önem taşımaktadır. Ekolojik giysiler, yumuşak ve hassas bebek ciltleri için uygun olmakla birlikte, ekolojik kumaşlar hafif ve yumuşak özellikleri nedeniyle daha konforlu bir his sağlamakta, alerjik sorunları minimize etmektedir. Ayrıca bu yüzeylerin nem emme özellikleri de daha iyidir. Tüm bu özelliklerle birlikte çevresel sorunlara karşı oluşturduğu farkındalık da birçok faaliyetin gelişmesine yol açmış [2], bu farkındalığa paralel olarak dünya üzerindeki örgütler de konu üzerindeki çalışmalarını hızlandırmışlardır.

Ekolojik gereksinimleri karşılayabilmek amacıyla, belirlenmiş zararlı kimyasalların kullanımına ilişkin yasaklar ve kısıtlamalar 1990’lı yılların başlarında Avrupa Tekstil Enstitüleri Birliği tarafından kabul edilmiş ve bu kapsamda ürünlerde kullanılabilecek zararlı maddelerin sınır değerlerinden yola çıkılarak gerekli maddeler için yasaklar getirilmiştir [7].

\subsection{Oeko-Tex (Eko-Teks) 100 Standardı}

Tekstil ürünlerindeki sertifikasyonların güvenilirliği, yapılan ölçümlerin sahip olduğu kalite standartlarına bağlı olmaktadır [8]. Bu nedenle uluslararası standartlar değerlendirilmekte, yeni standartlar geliştirilmekte, mevcutlar ise yenilenmekte ve böylelikle ihtiyaca yönelik yeni standartlar oluşturulmaktadır [1].

Dünya'da başlayan ekolojik eğilim ve bunun üzerine yapılan çalışmalar sonucunda özel çevre etiketleri oluşturulmuştur. En yaygın olarak kullanılan etiket, "Oeko-Tex (Eko-Teks) 100" standardıdır. Bu standart, 1992 yılında 17 Avrupa Tekstil Enstitüsü tarafından işlenerek kabul edilmiş ve bugün için dünyanın 40 ülkesinde geçerliliğini sürdürmektedir. Bu etikete sahip olan ürünler insan sağlığına ve çevreye zarar vermeyen ürünlerdir. Eko-Teks 100 etiketi sadece tekstil ürünleriyle ilgili olmakta, tekstil üretim sürecinin çevreyle ilgili yönünü ele almamaktadır. Eko-Teks 100 standardı, tekstilde Eko-Teks işaretinin kullanım yetkisinin verilmesine ilişkin genel koşulları belirlemekte, tekstil ürünleri için geçerli düzenlemeleri, kalite kontrolün oluşturulması, test metotlarının tanımı, uygulama kurallarını kapsamaktadır [3, 9]. Eko-Teks birliğinin amacı ise, tekstil ürünlerinde zararlı kimyasal maddelerin kullanılmadığını garanti etmek ve sertifikasız ürünlerde ortaya çıkabilecek ekolojik risk ve tehlikeler hakkında farkındalık yaratmaktır. Standartların çeşitliliği, sadece insan sağlığını değil, aynı zamanda çevresel boyutu da kapsamaktadır [10]. 
$\mathrm{Bu}$ standart kapsamındaki ürün sınıfları, ürünlerin kullanım amaçlarına göre belirlenmiştir. Ürün sınıfları genel olarak ürünlerin karşılaması gereken gereklilikler ile uygulanan test yöntemleri bakımından farklılık göstermektedir. Bunlar;

- Bebeklere yönelik ürünler (Ürün Sınıfı 1): Bu standart kapsamında bebek ürünleri, bebeklere ve 36 aydan küçük çocuklara yönelik eşyaların üretimi için öngörülmüş olan, deri kıyafetler hariç olmak üzere bütün eşyalar, ön ürünler ve aksesuarlardır.

- Cilde doğrudan temas eden ürünler (Ürün Sınıfı 2)

- Cilde doğrudan temas etmeyen ürünler (Ürün Sınıfı 3)

- Döşemelik malzemelerdir (Ürün Sınıfı 4) [11].

\section{TEKSTIL ÜRÜNLERINDE KULLANILAN BAZI ZARARLI MADDELER ve ETKILERI}

Tekstil ürünlerinin insan sağlığına zarar vermemesi için sağlık örgütleri tarafından tekstil ürünlerinde bulunabilecek zararlı maddelere yönelik birtakım kısıtlamalar getirilmiştir. $\mathrm{Bu}$ zararlı maddeler; kanserojen özellik gösterebildiği, toksik olabildiği, çeşitli vücut sistemleri üzerinde olumsuz etki yaratabildiği, ciltte tahriş, iritasyon ve alerjiye neden olabildiği için özellikle bebek giysilerinde standartlara uyulması çok önemlidir. Çünkü bu standartlar çeşitli maddelerin sağl1k üzerinde olumsuz etki yaratmayacağı tespit edilmiş limit değerlerini belirlemektedir. $\mathrm{Bu}$ bölümde ise, bebek tekstil ürünlerinde bulunabilecek bazı zararlı maddelerin sağlık üzerindeki etkileri ile 2007 yılından itibaren Eko-Teks 100 standardınca kabul edilmiş sınırlandırma ve yasaklamaların süreci birlikte incelenmiştir.

pH Değeri Yüksek Maddeler: pH değeri yüksek olan kumaşlar, kolaylıkla cilde zarar vererek alerjik reaksiyonlara yol açabilmektedir [12]. Üretim aşamalarında kullanılan her kimyasalın bitmiş üründeki $\mathrm{pH}$ değerine etkisi bulunmaktadır. $\mathrm{pH}$ değeri, yıkama ve nötrleştirme basamaklarında kontrol altına alınabilmektedir [13].

Eko-Teks 100 standardına göre pH tayini ISO 3071 (Potasyum klorür çözeltisi) uyarınca tespit edilmektedir [14]. Bu standart kapsamında $\mathrm{pH}$ değerinin alt ve üst limit değeri sırasıyla 4.0 ve 7.5 olarak kabul edilmiştir [15]. Ayrıca 2007 yılından itibaren incelen standartlarda pH değerinin limitine ilişkin herhangi bir değişikliğin yapılmadığı görülmüştür.

Formaldehit: Tekstilde formaldehit açığa çıkaran bileşikler; çekmezlik ve buruşmazlık apresi, bitim işlemi, boya ve baskının korunması ve fikse edilmesi için kullanılan kimyasalları içermektedir [13]. Formaldehit, temas miktarı ve yoluna göre kontakt dermatite, alerjik reaksiyona, solunum yollarında irritasyona ve gözlerde yanmaya neden olabilmektedir. Ayrıca 
formaldehit, Uluslararası Kanser Araştırma Ajansı (LARC) tarafından hazırlanan kanserojen maddeler listesinde de yer almaktadır [16].

Eko-Teks 100 standardına göre formaldehit tespiti için öncelikle numuneye formaldehitin varlığına ilişkin kalitatif analiz uygulanmaktadır. Sonrasında formaldehit içeriğinin kantitatif analizi yapılmaktadır. Bu kapsamda uygulanacak test, 112 sayılı Zararlı Maddeler İçeren Evrensel Ürünlerin Kontrolüne İlişkin Japonya Kanunu'nda ön görülen test yöntemlerine göre yürütülmektedir. Bahsi geçen yöntemler gereği, sulu ekstratlarda serbest ve kısmen salınımlı formaldehit içeriği asetilasyon yöntemi ile spektrofometrik bir şekilde hesaplanmaktadır [14]. Bu standart kapsamında bebek ürünleri için kabul edilebilir formaldehit miktarının üst sınırı 20 ppm olarak belirlenmiştir $[15,17]$.

Pestisitler: Pestisitler, doğal liflerin yetiştirilmesi sırasında kullanılan gübrelerin ve zirai ilaçların içinde bulunmakta ve son kullanıma kadar ayrışmamaktadırlar. İnsan ve hayvanlardaki toksik maddeleri arttırmakla birlikte cilt tarafından da kolaylıkla emilebilmektedir. Dolayısıyla insanlardaki hormon dengesi, üreme ve bağışıklık sistemlerine zarar verebilmektedir [12, 13]. Eko-Teks 100 standardında yer alan pestisitlerin testleri 'clean-up' (örneklerin istenmeyen bileşenlerden temizlenmesi) yapılan ekstraktların selektif tespiti ile gaz kromatografisinde gerçekleştirmektedir [14]. 2007 yılından itibaren yapılan incelemelerde toplam pestisit miktarının değişmediği ve üst limit değerinin $0,5 \mathrm{mg} / \mathrm{kg}$ olduğu tespit edilmiştir [15].

Ağır Metaller: Ağır metaller, bazı boyaların ve pigmentlerin yapımında kullanılmaktadır. Ayrıca bitkilerin topraktan almaları sonucunda doğal liflerde de bulunabilmektedir. Ayrıca metaller tekstil ürünlerine boyama ve bitim işlemleri yoluyla da bulaşabilmektedir [12]. Eksrakte olabilen ağır metallerin sınır değerleri eşik limit değerleri esasına ve içme suyu için olan tavsiyelere dayanmaktadır. Yani tekstil materyali ile temas eden derinin yüzeyinde oluşan terde, içme suyundan daha yüksek konsantrasyonda ağır metale izin verilmemektedir. İnsan vücudu ise teri absorbe etmektense, çıkarmaya eğilimli olduğu için eko-tekstiller için izin verilen ekstrakte olabilen ağır metallerin çok düşük olan maksimum seviyeleri için toksikolojik bir durum bulunmamaktadır [18].

Ağır metaller, karaciğer, böbrek gibi iç organlarda birikme eğilimi göstermektedir. Yüksek düzeylerde birikim meydana geldiği zaman sağlık üzerindeki etkileri büyük olabilmektedir. Örneğin nikel; giysiler üzerindeki düğme, fermuar ve perçin gibi metal aksesuarlarda kullanılan alaşımlarda bulunmaktadır. Bazı insanlar nikele karşı alerjik reaksiyon gösterebilmekte ve nikel barındıran aksesuarlarla uzun süreli temas halinde ciddi cilt tahrişi yaşayabilmektedir [12]. 
Kurşun ve kadmiyum ise ciltte tahrişe neden olmakla beraber karaciğer, böbrek ve sinir sistemine de hasar verebilmektedir [19, 20]. Bunların dışında arsenik ve cıva da çok yükssek toksik özelliğe sahiptir [18]. Ayrıca cıva; büyüme geriliklerine, D vitamini metabolizma bozukluklarına, hemoglobin sentezinde inhibisyona sebep olabilmektedir. Krom ise deri ile temas derecesine ve derinin kromla temas eden kısımların hassasiyetine göre ülser oluşmasına neden olabilmektedir [16]. Sonuç olarak ağır metallerin olası olumsuz özelliklerini; toksik olmaları, sinir sistemini etkileyebilmeleri, kanser oluşmasına neden olabilmeleri, deri irritasyonlarına yol açabilmeleri ve alerjik etkiler oluşmasına sebep olabilmeleri olarak özetleyebilmekteyiz [18].

Eko-Teks 100 standardı kapsamında ağır metal tayini testleri, atomik absorpsiyon skeptrometrisi (AAS) veya indüktif eşleşmiş plazma (ICP) ve spektrofotometri yöntemleriyle gerçekleştirilmektedir [14]. Eko-Teks 100 kapsamında 2007 yılından itibaren ekstrakte olabilen ağır metaller bölümünün limit değerlerinde bir değişiklik yapılmamıştır. Digest edilmiş örnekte ağır metaller için ise Şekil 1'de gösterilen değişiklikler uygulanmıştır. Standarda göre kurşun miktarının arttırılmasında bir sakınca görülmemiş, kadmiyum limit değeri ise azaltılmıştır [15].

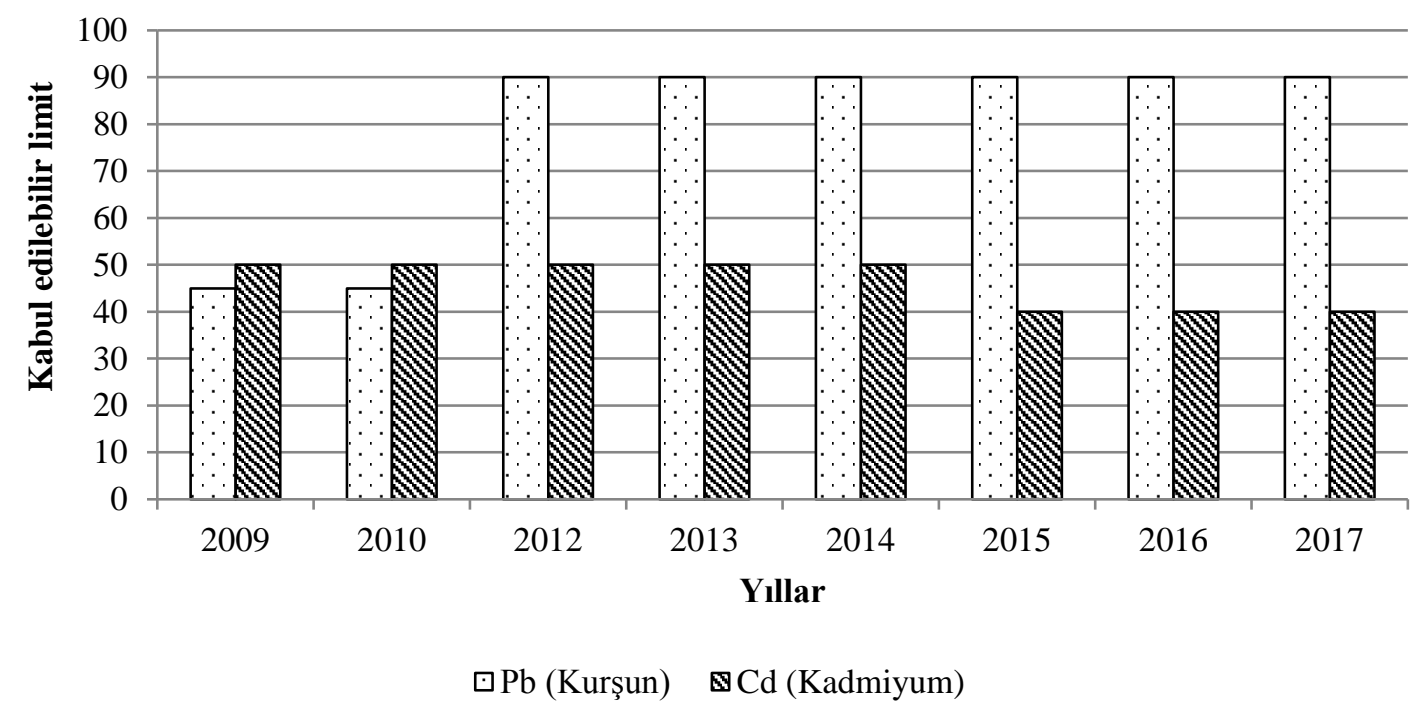

Şekil 1. Yıllar Bazında Digest Edilmiş Örnekte Ağır Metallerde Kabul Edilebilir Limit Değerleri [mg/kg].

Uçucu Organik Bileşikler: Bu bileşikler kansorejen etki gösterebilmekte, yüksek toksik özellik gösterebilmekte ve güçlü tahriş edici etkilere neden olabilmektedir [12].

Standart kapsamında bu bileşikler gaz kromatografisi yolu ile analiz edilmektedir [14]. Verilere göre uçucu organik bileşiklerin üst limit değerlerinin 2007 y1lından itibaren değişmediği ve 0.5 $\mathrm{mg} / \mathrm{m}^{3}$ olduğu görülmüştür [15]. 
Klorlu Fenoller: Mantar kaynaklı küfün oluşmasını önlemek amacıyla, ürünlere doğrudan PCP (pentachlorophenol) gibi klorlu fenoller uygulanmaktadır. PCP çok toksik bir maddedir ve kanser yapıcı bir ajan olarak değerlendirilmektedir [12]. TrCP (trichlorophenols), DCP (dichlorophenols), MCP (monochlorophenols) genel olarak ciltte ve gözde tahrişe neden olmakta ve sinir sistemine, solunum sistemine ve ciğerlere hasar verebilmektedir [21-23].

Eko-Teks 100 standardına göre fenol içeriğinin tayini, gaz kromatografisi ile yapılmakta olup yapılacak bu analizler için kütle selektif (MSD) veya elektron tarama (ECD) dedektörleri kullanılabilmektedir [14]. Yapılan incelemeler sonucunda bebek giysilerinde yetişkin giysileri için kabul edilebilir değerin altı ile on katı hassasiyetinde sınırlandırılma yapıldı̆̆ edilmiştir. Ayrıca PCP ve TeCP (tetrachlorophenols) limit değerleri için 2007 yılından itibaren bir değişiklik uygulanmadığı, Şekil 2'de gösterildiği üzere TrCP'nin değerlendirilmesine 2014 yılında başlandığı, 2016 yılı itibari ile DCP ve MCP için de kısıtlama getirildiği görülmüştür [15].

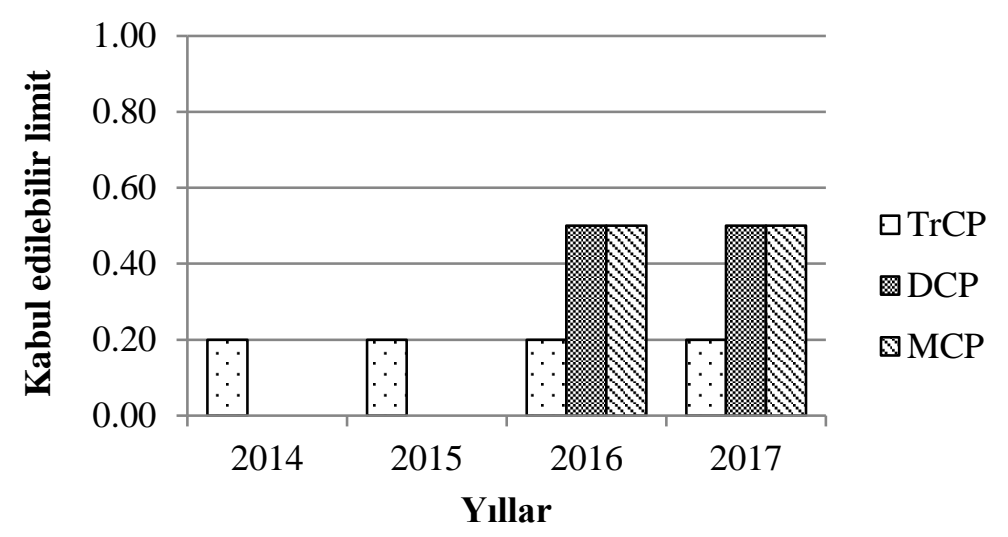

Şekil 2. Yıllar Bazında Klorlu Fenollerde Kabul Edilebilir Limit Değerleri [mg/kg].

Ftalatlar: Ftalatlar temel olarak plastiklere, özellikle de PVC (polyvinyl chloride) ürünlere plastik özelliğini vermede kullanılmaktadır. Ftalatların plastiklerle kimyasal bir bağı bulunmadığından, kullanım ömürleri boyunca çevreye yayılmaktadır. Ftalatlara, hava ve toz da dâhil olmak üzere iç ortamlarda sıklıkla rastlanmaktadır. Genelde insan dokusunda olmak üzere çocuklarda yetişkinlere nazaran daha yüksek seviyelerde görülmektedir. Avrupa Birliği'nin 2002 yılında yayınladığı endokrin bozucular ile ilgili raporda yüzlerce kimyasal madde içinde çevre ve insan sağlığına zararı net olarak gösterilmiş 60 madde bulunmaktadır. Bu maddeler arasında ftalatlar da yer almaktadir [24].

Bebeklerdeki yüksek hassasiyet sebebiyle ftalat nedenli oluşabilecek olumsuz etkilerin en fazla bu dönemde ortaya çıkabileceği görülmektedir. Bu etkilerin özellikle üreme sistemi olmak üzere vücutta ciddi ve kalıcı etkiler bırakabileceği düşünülmektedir. Doğal yaşam ve insan 
üzerindeki zehirli etkisinin yanı sıra hormon aksatıcı etkilerine ilişkin önemli endişeler bulunmaktadir [25].

Eko-Teks 100 standardı kapsamında 2007 yılından itibaren ftalatın limit değerinde herhangi bir değişiklik yapılmadığı tespit edilmiştir. Standarda göre bir örnekte bulunabilecek ftalat ağırlığı ürün ağırlığının \%0,1'ini geçmemelidir [15].

Kimyasal Atıklar: Bu atıklar, ciltte ve gözde tahrişe neden olabilmektedir [26-28]. Eko-Teks 100 standardına göre OPP (o-phenylphenol) tayini gaz kromatografisi ile SCCP (kısa zincirli klorlanmış parafin) ve DMFu (dimethylfumarate) tayini ise test edilecek maddenin maddenin organik çözücülerle ekstraksiyonu ile yapılmaktadır [14]. 2007 yılından itibaren incelenen EkoTeks 100 standartlarına bakıldığında bu yıldan itibaren OPP ve arilaminlere ilişkin limit değerlerin olduğu görülmektedir. Buna göre OPP'nin limit değeri $50 \mathrm{mg} / \mathrm{kg}$ olarak belirlenirken, üründe arilamin olmaması zorunlu kılınmıştır. TCEP (tris-(2-chloroethyl)) ve SCCP’ye yani kısa zincirli klorlanmış parafinlere yönelik limit değerler standarda 2012 yılında eklenmiştir. Bu atıkların limit değerleri ağırlıkla ilişkilendirilmiş olup, mamul ağırlı̆̆ının \%0.1'inden fazla olamayacağı belirlenmiştir. 2013 yılında DMFu için de $0.1 \mathrm{mg} / \mathrm{kg}$ 'lık limit değer standarda eklenerek kimyasal atıklara ilişkin içerik genişletilmiştir [15].

Alev Geciktiriciler: Yüksek dozda alev geciktiriciler ile uzun süreli temas, bağışıklık sisteminin zayıflamasına ve hafiza kaybına yol açabilmektedir [12]. Bu nedenle bu ürünlerin kullanımına standart kapsamında izin verilmemektedir [15].

Organokalay Bileşikleri: $\mathrm{Bu}$ bileşikler; çorap, ayakkabı ve spor giysilerinde terleme neticesinde ortaya çıkan bakteri degradasyonunu ve buna bağlı hoş olmayan kokuları önlemek amacıyla kullanılmaktadır. Cilt yoluyla emilebilen bu maddelerin üreme bozukluklarına yol açtığından şüphe edilmektedir [12].

$\mathrm{Bu}$ maddelerin yüksek konsantrasyonları, toksik etki gösterdiği için sınır değerinin arttırılmasında sakınca görülmemiştir. Bebeklerde, yetişkin giysileri için kabul edilebilir değerin iki katı hassasiyetinde sınırlandırma yapılmıştır.

İlgili standart kapsamında organokalay bileşiklerinin tayini için, tekstil malzemeleri organik bir çözücü ile ekstarkte edilerek ardından sodyum terraetil borat ile türevlendirilmektedir. Testler, 'clean-up' ekstratlarının selektif tespiti ile gaz kromatografisinde gerçekleştirilmektedir [14]. 2007 yılında sadece DBT (dibutyltin) ve TBT (tributyltin) bileşiklerine ilişskin kısıtlama bulunurken daha sonraki yıllarda başka bileşikler için de kısıtlamalar eklenmiştir [15]. Bu kapsamda TPhT (triphenyltin), DOT (dioctyltin), DMT (dimethyltin), DPhT (dibutyltin), MBT 
(monobutyltin), MOT (monococtyltin), MMT (öonomethyltin), TeBT (tetrabutyltin), TCyHT (tricylcohexyltin), TMT (trimethyltin), TOT (trioctyltin) ve TPT (tricopyltin) için yapılan düzenlemeler Şekil 3'de gösterilmektedir.

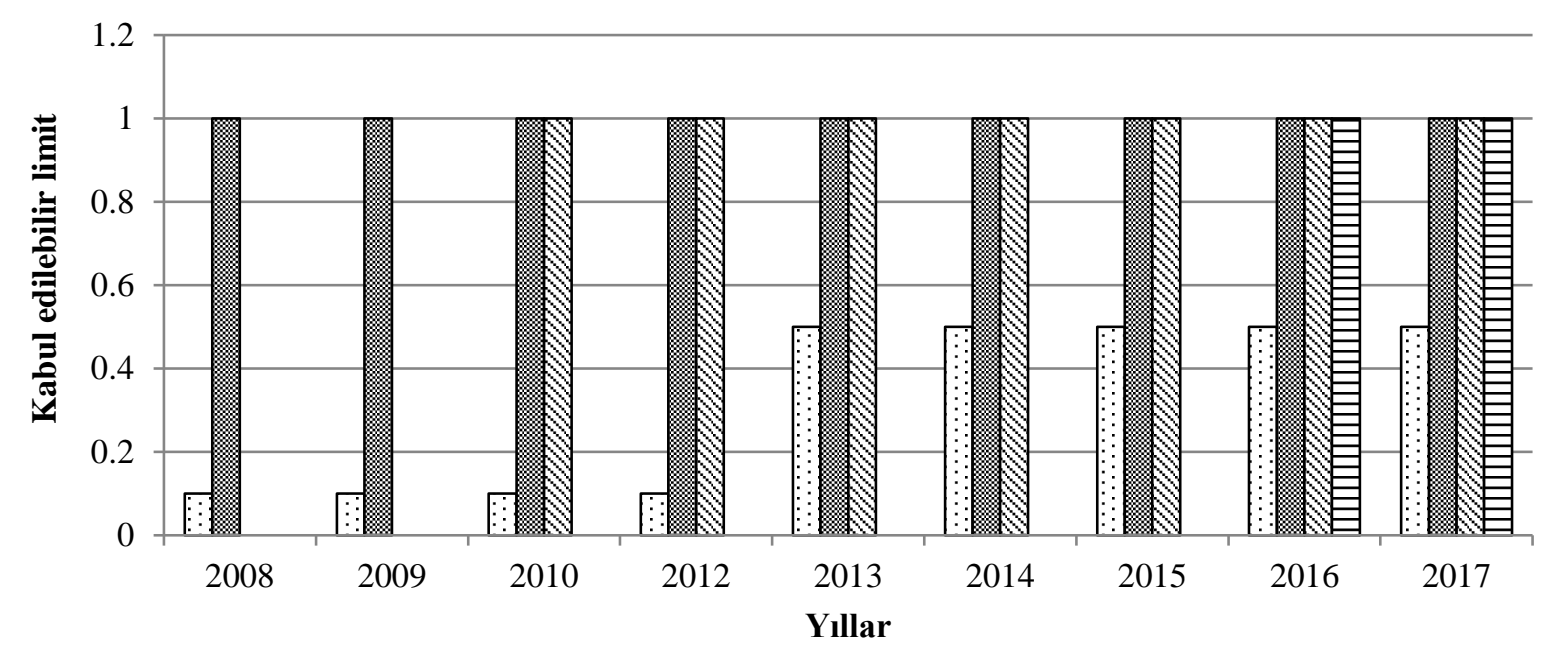

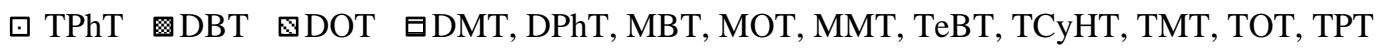

Şekil 3. Yıllar Bazında Organokalay Bileşiklerde Kabul Edilebilir Limit Değerler [mg/kg].

Azo boyarmaddeler: Bazı azo boyarmaddeleri, boyama sonucunda serbest amino gruplarının oluşmasına neden olmaktadırlar. Bugün dünya üzerinde yaklaşık olarak 3500 adet azo boyarmadde bulunmaktadır ve bu grup, tüm boyarmaddelerin \%65'ini oluşturmaktadır [13]. Azo boyaları derideki bakteriler veya deriden emildikten sonra gastrointestinal sistem ve karaciğerdeki enzimlerin etkisiyle aromatik aminlere dönüşmektedir. Aromatik aminlerin insan sağlığı üzerinde deride sensitizasyon, genotoksik ve kanserojen etkileri olduğu bilinmektedir. Ayrıca birçok azo boyarmaddenin uygun koşullar altında redüktif parçalanması sonucunda kanserojen arilamin bileşiklerini oluşturduğu saptanmıştır [16].

Eko-Teks 100 standardı kapsamında azo boyarmaddelerine ilişkin analiz yöntemleri EN 143621 ve EN 14362-3 normlarına göre yürütülmektedir [14]. Türkiye'de yasaklı arilaminler ve bunları içeren azo boyaların deri ve tekstilde kullanımı Sağlık Bakanlığının yazısı ile Mart 1995 tarihinden itibaren yasaklanmıştır [13].

Polisiklik ve Aromatik Hidrokarbonlar (PAH): Bu ürünler genel olarak cilt üzerinde alerjik etki göstermekte, genetik rahatsızlıklara neden olabilmekte, kanser riski oluşturmakta, organlara ve doğmamış çocuklara zarar verebilmektedir [29-35].

Polisiklik aromatik hidrokarbon (PAH) içeriğinin tayini, test materyalinin organik bir çözücü ile ekstarksiyonu ile yapılmaktadır. 'Clean-up' işleminden sonra gaz kromatografisi ile analiz edilmektedir [14]. Eko-Teks 100 standartları incelendiğinde bu bölümdeki ilk sınırlandırmanın 
2010 yılında benzo(a)piren için yapıldığı görülmüştür. Bu yılda limit değer $1 \mathrm{mg} / \mathrm{kg}$ olarak belirlenmesine rağmen 2013 yılında değerin $0.5 \mathrm{mg} / \mathrm{kg}$ ’a düşürüldüğü tespit edilmiştir. 2014 yılından itibaren ise başka hidrokarbonlar da limit değerleri $0.5 \mathrm{mg} / \mathrm{kg}$ olacak şekilde standarda eklenmiştir [15]. Ayrıca bu bölüm için tüm standart incelendiğinde, sınıf 1'de sınıf 2'ye nazaran kabul edilebilir limit değerlerin iki kat yüksek hassasiyetle belirlendiği de görülmektedir.

Çözücü Atıkları: Çözücü atıkları ciltte ve gözde tahrişe neden olmaktadır. Ayrıca DMF (Dimethylformamide) mukoz zarlarını ve üst solunum yollarını tahriş edebilen ve zararlı olabilen bir bileşiktir [12, 36].

Eko-Teks 100 standardına göre çözücü kalıntılarının ölçülmesi için kullanılan metot, tekstil ürününün bir organik çözücü madde ekstraksiyonunu takiben gaz kromatografisi ile analizine dayanmaktadır [14]. Bu bölüm için limit değerler, atık ağırlığının materyal ağırlığına oranıyla ifade edilmektedir. Yapılan incelemeler doğrultusunda ilk sınırlandırmanın NMP (1-Methyl-2pyrrolidone) ve DMAc (N,N-Dimethylacetamide) için 2012 yılında \%0.1 (\%W) olarak yapıldığg görülmektedir. 2013 yılında DMF için de aynı sınır değer (\%0.1) belirlenmiş olup, 2015 yılında formamit için ağırlıkça limit değer \%0.02 olarak belirlenmiştir [15].

PFC's (Perflorine Edilmiş Bileşikler): PFOS (Perfluoroctansulfonate) ve PFOA (Perfluorooctane sulfonates); tekstil ürünlerinde su geçirmezlik sağlamak için yaygın olarak kullanılmaktadır. Biyolojik birikim özelliği çok yüksek olan bu madde toksik olarak değerlendirilmektedir [12]. Ayrıca kansorejen etkileri de tespit edildiğinden kullanımları kısıtlanmıştır [13].

Standarda göre bu bileşiklerin tespiti için metal ekstraksiyonu ve müteakip bir LC/MS/MS (sıv1 kromatografisi-kütle-kütle spektrometresi) analizini içeren bir yöntem kullanılabilmektedir [14]. Eko-Teks 100 standardı kapsamında perflorine edilmiş bileşiklerde ilk olarak 2009 yılında PFOS için $1 \mu \mathrm{g} / \mathrm{m}^{2}$ ve PFOA için $0,1 \mathrm{mg} / \mathrm{kg}$ olmak üzere limit değerler belirlenmiştir. Ancak 2015 yılında PFOA’nın birimi değiştirilerek limit değer $1 \mathrm{mg} / \mathrm{kg}$ olacak şekilde güncellenmiştir. 2014 yılından itibaren ise PFDUdA (henicosafluoroundecanoic acid), PFDoA (tricosafluorododecanoic acid), PFTrDA (pentacosafluorotridecanoic acid), PFTeDA (heptacosafluorotetradecanoic acid) bileşikleri için $0.05 \mathrm{mg} / \mathrm{kg}$ değerinde sınırlandırmalar getirilmiştir [15].

Yüzey Aktif ve Nemlendirici Ajan Atıkları: Bu maddeler toksik olup suyu kirletmektedirler. Ancak suyla kolaylıkla uzaklaştırılamayan bu maddeler, hormon düzenleme sistemini bozabilmekte ve östrojenik olumsuz etkilere yol açabilmektedir [12]. 
Yüzey aktif ve nemlendirici ajan atığı içeriğinin tayini, test materyalinin organik bir çözücü ile ekstarksiyonuyla yapılmaktadır. Ekstrakt sıvı kromatografisi-kütle spektrometresi (LC/MS) ile analiz edilmektedir [14]. Değişen standartlar incelendiğinde ise NP (nonylphenol), OP (octylphenol), OP(EO) (octylphenolethoxylates) ve NP(EO) (nonyl phenolethoxylates) atıkları için ayrı ayrı olmak üzere 2012 yılında limit değerler getirildiği görülmüştür. 2013 yılından itibaren ise Şekil 4’te gösterildiği üzere toplam miktar için sınırlandırma getirilmiştir [15].

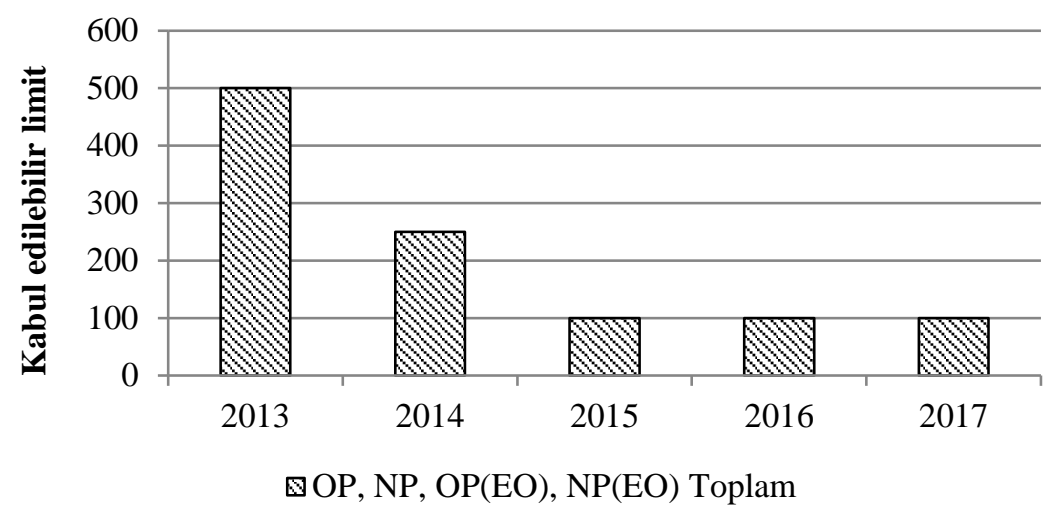

Şekil 4. Yıllar Bazında OP ve NP OP(EO), NP(EO)'nın Toplamına Ait Limit Değerler [mg/kg].

\section{SONUÇ}

Bebek cildinde koruyucu yağ tabakasının tam oluşmamış olması, en ufak bir tahriş edici ya da zararlı olan bir madde ile temas ettiğinde kızarıklığa neden olabilmektedir. Temas eden yüzey, zararlı kimyasalları barındırdığı takdirde bazen geri dönüşü olmayan sağlık sorunları oluşabilmektedir. Bu kimyasalların büyük bir çoğunluğunun da vücutta birikebileceği bilinmektedir. Ayrıca zararlı kimyasalların bebek giysilerinde kullanılması, bu kimyasalların üretimi sırasında veya doğrudan ürünler yoluyla doğaya salınmasına da neden olmakta ve ekolojiyi kötü yönde etkilemektedir.

Eko-Teks 100, tekstil ürünlerinde kullanılabilecek kimyasalların analizlerini yaparak insan sağlığına zarar vermeyecek limit değerler doğrultusunda sınırlandırmaların yapıldığı uluslararası bir standarttır. Bu standartta zaman içinde tehlikeli olduğu anlaşılan içeriklere ait eklemeler ve değişiklikler yapılmıştır. Son olarak 2017 yılında gelen bir güncelleme ile cilde dolayısıyla sağlığa da zarar veren ultraviyole 1şınları da düşünülerek UV stabilizörler için de limit değerler getirilmiştir. Genele bakıldığında ise 2007-2017 yılları arasında bebek sınıfı ürünleri için toplamda 616 adet limit değer görülmektedir. Yapılan incelemeler doğrultusunda ise bu değerlerin 53 adedinde değişiklik yapıldığ güncellendiği tespit edilmiştir. Ayrıca tüm sınıflar incelendiğinde, bebek giysileri için kabul edilebilir limit değerlerin yetişkin giysilerine nazaran çok daha hassas olduğu açıkça 
görülmektedir. Bu nedenle tekstil ürünlerinde kullanılan zararlı kimyasalların önemi herkes tarafından daha iyi kavranmalı ve bebeklere alınacak ürünlerde mutlaka geçerli bir standart onayı bulunmasına dikkat edilmelidir. Aksi takdirde bebeklere tekstil ürünü ile birlikte zehir giydirilebileceği unutulmamalıdır.

\section{KAYNAKLAR}

[1] N.D. Kariuki, X.Y. Wu, C.C. Gao and X.M. Ding, Clothing standards compliance assessment. International Journal of Clothing Science and Technology, 26(5) (2014) 377 394.

[2] T. Gümüşer, Ekolojik bebek giysilerinde doğal liflerin önemi. Sanat - Tasarım Dergisi, 1 (4) (2013) 23-34.

[3] N. Kurtoğlu, D. Şenol, Tekstil ve ekolojiye genel bakış, karsinojen ve allerjik etki yapabilen tekstil kimyasallart. KSÜ Fen ve Mühendislik Dergisi, 7(1) (2004) 26-31.

[4] M.O. Bulut, Üretim kalite değerlerinin belirlenmesi. The Journal of Textiles and Engineers, 14(68) (2007) 20-27.

[5] D.T. Cebeci, Ekolojik tekstiller ve üniversite ögrencilerinin ekolojik tekstiller konusundaki farkındalıklarının incelenmesi. Akdeniz Sanat Dergisi, 4(8) (2012) 69-72.

[6] O. Oral, E. Dirgar and Ç. Erdoğan, Tekstil ve hazır giyim üretiminde ekoloji. Akdeniz Sanat Dergisi, 4(8) (2012) 31-34.

[7] E.K. Choe, Y.Z. Kim, Y.D. Cho and S.H. Son, Study on analytical scheme for human ecological quality control of chromium-complex acid dyes. Textile Research Journal, 86(17) (2016) 1847-1858.

[8] G.R. Baglio, L. Ampoldi, Quality control and certification of textile products. Tinctoria, 94(3) (1997) 66-68.

[9] İzmir Tic. Odası Arge Bülteni. "Dünyada Ve Türkiye'de Tekstil Ve Konfeksiyon Sektörleri", n.d. Web. 11 Oct. 2017.

<http://Www.İzto.Org.Tr/Portals/0/Iztogenel/Dokumanlar/Tekstil_Sektorunde_Cevre_Ak imi_H_Uzunoglu_25.04.2012\%2010-40-12.Pdf >.

[10] What you don't know about textiles can harm you! Textiles Magazine, 33:3 (2006) 22-23.

[11]B.J. Mccarthy, B.C. Burdett, Eco-labelling and textile eco-labelling. Coloration Technology, 28(1) (1998) 61-70.

[12] İntertek. "Tekstil Kimyasal Testleri" n.d. Web. 22 Dec. 2017. <http://intertekturkey.com/tekstil-kimyasal-testleri/>.

[13] TMMOB Kimya Mühendisleri Odası. "Tekstil Üretimi Ve Yardımcı Kimyasallar", n.d. Web. 22 Dec. 2017. 〈http://www.meslekiyayin.com/images/111_0014.pdf>.

[14] Oeko-Tex. "Testing Methods" n.d. Web. 09 Apr. 2017. <https://www.oekotex.com/media/init_data/downloads/STANDARD\%20100\%20by\%20OEKO-

TEX\%C2\%AE\%20-\%20Testing\%20Methods_tr.pdf>.

[15] Oeko-Tex. "Limit values and fastness" n.d. Web. 09 Apr. 2017. <https://www.oekotex.com/en/business/certifications_and_services/ots_100/ots_100_limit_values/ots_100_1 imit_values.xhtml>. 
[16]E. Örün, Giysiler ve çocuk să̆ğğı: ne giysin? Nasıl yıkansın?. Cocuk Sagligi ve Hastaliklari Dergisi, 58(1), (2015) 43-49.

[17]G. Gülümser, Ege bölgesi deri işletmelerinde üretilen giysilik derilerde formaldehit miktarları üzerinde bir araştırma. Ege Üniversitesi Ziraat Fakültesi Dergisi 38(2-3), (2001) 151-156.

[18] ScienceLab. "Material Safety Data Sheet Lead MSDS", n.d. Web. 23 Dec. 2017. <http://www.sciencelab.com/msds.php?msdsId=9927204>.

[19] Science Lab. "Material Safety Data Sheet Cadmium MSDS", n.d. Web. 23 Dec. 2017. <http://www.sciencelab.com/msds.php?msdsId=9923223>.

[20]N. Seventekin, E. Özdoğan, Eko tekstiller açısından toksik ă̆ır metaller. Tekstil ve Konfeksiyon Dergisi, 8(1) (1998) 58-64.

[21] ScienceLab. "Material Safety Data Sheet 2,4,5-Trichlorophenol MSDS", n.d. Web. 23 Dec. 2017. < http://www.sciencelab.com/msds.php?msdsId=9927633>.

[22]Alfa Easar. "Safety Data Sheet" n.d. Web. 23 Dec. 2017. $<$ https://www.fishersci.com/shop/msdsproxy?productName=AAA1532806\&productDesc ription $=3+5-$

DICHLOROPHENOL+98\%2B\%25+5G\&catNo=AAA1532806\&vendorId=VN0002424 $8 \&$ store Id $=10652>$.

[23]Praxair. "Chlorine Safety Data Sheet P-4580", n.d. Web. 23 Dec. 2017. $<$ http://www.praxair.com/-/media/documents/sds/chlorine-cl-2safety-data-sheet-sdsp4580.pdf $>$.

[24]E. Durmaz, E.N. Özmert, Fitalatlar ve çocuk sağlı̆̆l. Cocuk Sagligi ve Hastaliklari Dergisi, 53(4) (2010) 305-317.

[25]Greenpeace. "Çocuk Ürünleri Test Raporu", n.d. Web. 30 Dec. 2017. <http://www.greenpeace.org/turkey/Global/turkey/image/2014/01/\%C3\%87ocuk\%20\%C 3\%BCr\%C3\%BCnleri\%20test\%20raporu\%20-\%20TR.pdf>.

[26]U.S. Environmental Protection Agency. "Short-Chain Chlorinated Paraffins (SCCPs) and Other Chlorinated Paraffins Action Plan" n.d. Web. 23 Dec. 2017. $<$ https://www.epa.gov/sites/production/files/201509/documents/sccps_ap_2009_1230_final.pdf>.

[27] Caymanchem. "Safety Data Sheet TCEP", n.d. Web. 23 Dec. 2017. <https://www.caymanchem.com/msdss/14329m.pdf>.

[28] Caymanchem. "Safety Data Sheet TCEP Dimethyl Fumarate", n.d. Web. 23 Dec. 2017. <https://www.caymanchem.com/msdss/14714m.pdf>.

[29]Fisher Scientific. "Safety Data Sheet", n.d. Web. 23 Dec. 2017. $<$ https://www.fishersci.com/shop/msdsproxy?storeId=10652\&productName=AC1056010 00\&productDescription $=\mathrm{BENZO}>$.

[30] Acros Organics. "Material Safety Data Sheet Benzo(e)pyrene", n.d. Web. 23 Dec. 2017. <http://www.t3db.ca/system/msds/attachments/000/001/806/original/T3D0226.pdf?1413 587749>.

[31]TCI America. "Material Safety Data Sheet", n.d. Web. 23 Dec. 2017. <http://www.t3db.ca/system/msds/attachments/000/001/783/original/T3D0039.pdf?1413 $587745>$. 
[32] Acros Organic. "Material Safety Data Sheet Chrysene", n.d. Web. 23 Dec. 2017. <http://www.t3db.ca/system/msds/attachments/000/001/288/original/T3D0137.pdf? 1413 587657>.

[33]Clearsynth, "Material Safety Data Sheet", n.d. Web. 23 Dec. 2017. <http://www.chemblink.com/MSDS/MSDSFiles/205-99-2_Clear\%20Synth.pdf>.

[34] Acros Organics, "Material Safety Data Sheet Benzo[k]fluoranthene", n.d. Web. 23 Dec. 2017. <http://apps.wku.edu/sds/uploads/docs/2259.pdf>.

[35]Fisher Scientific. "Safety Data Sheet", n.d. Web. 23 Dec. 2017. <https://www.fishersci.com/shop/msdsproxy?storeId=10652\&productName=AC4064300 10\&productDescription=DIBENZ>.

[36]Labchem. "Material Safety Data Sheet Formamide", n.d. Web. 23 Dec. 2017. <http://www.labchem.com/tools/msds/msds/75482.pdf>. 